\title{
The effectiveness of research implementation strategies for promoting evidence-informed policy and management decisions in healthcare: a systematic review
}

\author{
Mitchell N. Sarkies ${ }^{* *}$, Kelly-Ann Bowles ${ }^{2}$, Elizabeth H. Skinner ${ }^{1}$, Romi Haas ${ }^{1}$, Haylee Lane ${ }^{1}$ and Terry P. Haines ${ }^{1}$
}

\begin{abstract}
Background: It is widely acknowledged that health policy and management decisions rarely reflect research evidence. Therefore, it is important to determine how to improve evidence-informed decision-making. The primary aim of this systematic review was to evaluate the effectiveness of research implementation strategies for promoting evidence-informed policy and management decisions in healthcare. The secondary aim of the review was to describe factors perceived to be associated with effective strategies and the inter-relationship between these factors.
\end{abstract}

Methods: An electronic search was developed to identify studies published between January 01, 2000, and February 02, 2016. This was supplemented by checking the reference list of included articles, systematic reviews, and hand-searching publication lists from prominent authors. Two reviewers independently screened studies for inclusion, assessed methodological quality, and extracted data.

Results: After duplicate removal, the search strategy identified 3830 titles. Following title and abstract screening, 96 full-text articles were reviewed, of which 19 studies (21 articles) met all inclusion criteria. Three studies were included in the narrative synthesis, finding policy briefs including expert opinion might affect intended actions, and intentions persisting to actions for public health policy in developing nations. Workshops, ongoing technical assistance, and distribution of instructional digital materials may improve knowledge and skills around evidenceinformed decision-making in US public health departments. Tailored, targeted messages were more effective in increasing public health policies and programs in Canadian public health departments compared to messages and a knowledge broker. Sixteen studies (18 articles) were included in the thematic synthesis, leading to a conceptualisation of inter-relating factors perceived to be associated with effective research implementation strategies. A unidirectional, hierarchal flow was described from (1) establishing an imperative for practice change, (2) building trust between implementation stakeholders and (3) developing a shared vision, to (4) actioning change mechanisms. This was underpinned by the (5) employment of effective communication strategies and (6) provision of resources to support change.

Conclusions: Evidence is developing to support the use of research implementation strategies for promoting evidence-informed policy and management decisions in healthcare. The design of future implementation strategies should be based on the inter-relating factors perceived to be associated with effective strategies.

Trial registration: This systematic review was registered with Prospero (record number: 42016032947).

Keywords: Implementation, Translation, Health, Policy, Management

\footnotetext{
*Correspondence: Mitchell.sarkies@monash.edu

${ }^{1}$ Kingston Centre, Monash University and Monash Health Allied Health

Research Unit, 400 Warrigal Road, Heatherton, VIC 3202, Australia

Full list of author information is available at the end of the article
} 


\section{Background}

The use of research evidence to inform health policy is strongly promoted [1]. This drive has developed with increased pressure on healthcare organisations to deliver the most effective health services in an efficient and equitable manner [2]. Policy and management decisions influence the ability of health services to improve societal outcomes by allocating resources to meet health needs [3]. These decisions are more likely to improve outcomes in a cost-efficient manner when they are based on the best available evidence [4-8].

Evidence-informed decision-making refers to the complex process of considering the best available evidence from a broad range of information when delivering health services $[1,9,10]$. Policy and management decisions can be influenced by economic constraints, community views, organisational priorities, political climate, and ideological factors [11-16]. While these elements are all important in the decision-making process, without the support of research evidence they are an insufficient basis for decisions that affect the lives of others $[17,18]$.

Recently, increased attention has been given to implementation research to reduce the gap between research evidence and healthcare decision-making [19]. This growing but poorly understood field of science aims to improve the uptake of research evidence in healthcare decision-making [20]. Research implementation strategies such as knowledge brokerage and education workshops promote the uptake of research findings into health services. These strategies have the potential to create systematic, structural improvements in healthcare delivery [21]. However, many barriers exist to successful implementation [22, 23]. Individuals and health services face financial disincentives, lack of time or awareness of large evidence resources, limited critical appraisal skills, and difficulties applying evidence in context [24-30].

It is important to evaluate the effectiveness of implementation strategies and the inter-relating factors perceived to be associated with effective strategies. Previous reviews on health policy and management decisions have focussed on implementing evidence from single sources such as systematic reviews $[29,31]$. Strategies that involved simple written information on accomplishable change may be successful in health areas where there is already awareness of evidence supporting practice change [29]. Re-conceptualisation or improved methodological rigor has been suggested by Mitton et al. to produce a richer evidence base for future evaluation, however only one high-quality randomised controlled trial has been identified since [9, 32, 33]. As such, an updated review of emerging research in this topic is needed to inform the selection of research implementation strategies in health policy and management decisions.
The primary aim of this systematic review was to evaluate the effectiveness of research implementation strategies for promoting evidence-informed policy and management decisions in healthcare. A secondary aim of the review was to describe factors perceived to be associated with effective strategies and the inter-relationship between these factors.

\section{Methods}

\section{Identification and selection of studies}

This systematic review was registered with Prospero (record number: 42016032947) and has been reported consistent with the Preferred Reporting Items for Systematic Reviews and Meta-Analysis (PRISMA) guidelines (Additional file 1). Ovid MEDLINE, Ovid EMBASE, PubMed, CINAHL Plus, Scopus, Web of Science Core Collection, and The Cochrane Library were searched electronically from January 01,2000 , to February 02, 2016, in order to retrieve literature relevant to the current healthcare environment. The search was limited to the English language, and terms relevant to the field, population, and intervention were combined (Additional file 2). Search terms were selected based on their sensitivity, specificity, validity, and ability to discriminate implementation research articles from non-implementation research articles [34-36]. Electronic database searches were supplemented by cross-checking the reference list of included articles and systematic reviews identified during the title and abstract screening. Searches were also supplemented by hand-searching publication lists from prominent authors in the field of implementation science.

\section{Study selection \\ Type of studies}

All study designs were included. Experimental and quasi-experimental study designs were included to address the primary aim. No study design limitations were applied to address the secondary aim.

\section{Population}

The population included individuals or bodies who made resource allocation decisions at the managerial, executive, or policy level of healthcare organisations or government institutions. Broadly defined as healthcare policy-makers or managers, this population focuses on decision-making to improve population health outcomes by strengthening health systems, rather than individual therapeutic delivery. Studies investigating clinicians making decisions about individual clients were excluded, unless these studies also included healthcare policy-makers or managers.

\section{Interventions}

Interventions included research implementation strategies aimed at facilitating evidence-informed decision- 
making by healthcare policy-makers and managers. Implementation strategies may be defined as methods to incorporate the systematic uptake of proven evidence into decision-making processes to strengthen health systems [37]. While these interventions have been described differently in various contexts, for the purpose of this review, we will refer to these interventions as 'research implementation strategies'.

\section{Type of outcomes}

This review focused on a variety of possible outcomes that measure the use of research evidence. Outcomes were broadly categorised based on the four levels of Kirkpatrick's Evaluation Model Hierarchy: level 1-reaction (e.g. change in attitude towards evidence), level 2-learning (e.g. improved skills acquiring evidence), level 3-behaviour (e.g. self-reported action taking), and level 4-results (e.g. change in patient or organisational outcomes) [38].

\section{Screening}

The web-based application Covidence (Covidence, Melbourne, Victoria, Australia) was used to manage references during the review [39]. Titles and abstracts were imported into Covidence and independently screened by the lead investigator (MS) and one of two other reviewers (RH, HL). Duplicates were removed throughout the review process using Endnote (EndNote ${ }^{\mathrm{m}}$, Philadelphia, PA, USA), Covidence and manually during reference screening. Studies determined to be potentially relevant or whose eligibility was uncertain were retrieved and imported to Covidence for full-text review. The lead investigator (MS) and one of two other reviewers (RH, $\mathrm{HL}$ ) then independently assessed the full-text articles for the remaining studies to ascertain eligibility for inclusion. A fourth reviewer (KAB) independently decided on inclusion or exclusion if there was any disagreement in the screening process. Attempts were made to contact authors of studies whose full-text articles were unable to be retrieved, and those that remained unavailable were excluded.

\section{Quality assessment}

Experimental study designs, including randomised controlled trials and quasi-experimental studies, were independently assessed for risk of bias by the lead investigator (MS) and one of two other reviewers ( $\mathrm{RH}$, HL) using the Cochrane Collaboration's tool for assessing risk of bias [40]. Non-experimental study designs were independently assessed for risk of bias by the lead investigator (MS) and one of two other reviewers $(\mathrm{RH}$, HL) using design-specific risk-of-bias-critical appraisal tools: (1) Quality Assessment Tool for Observational Cohort and Cross-Sectional Studies from the National
Heart, Lung, and Blood Institute (NHLBI; [41], February) and (2) Critical Appraisal Skills Program (CASP) Qualitative Checklist for qualitative, case study, and evaluation designs [42].

\section{Data extraction}

Data was extracted using a standardised, piloted data extraction form developed by reviewers for the purpose of this study (Additional file 3). The lead investigator (MS) and one of two other reviewers (RH, HL) independently extracted data relating to the study details, design, setting, population, demographics, intervention, and outcomes for all included studies. Quantitative results were also extracted in the same manner from experimental studies that reported quantitative data relating to the effectiveness of research implementation strategies in promoting evidence-informed policy and management decisions in healthcare. Attempts were made to contact authors of studies where data was not reported or clarification was required. Disagreement between investigators was resolved by discussion, and where agreement could not be reached, an independent fourth reviewer (KAB) was consulted.

\section{Data analysis}

A formal meta-analysis was not undertaken due to the small number of studies identified and high levels of heterogeneity in study approaches. Instead, a narrative synthesis of experimental studies evaluating the effectiveness of research implementation strategies for promoting evidence-informed policy and management decisions in healthcare and a thematic synthesis of non-experimental studies were performed to describe factors perceived to be associated with effective strategies and the interrelationship between these factors. Experimental studies were synthesised narratively, defined as studies reporting quantitative results with both an experimental and comparison group. This included specified quasi-experimental designs, which report quantitative before and after results for primary outcomes related to the effectiveness of research implementation strategies for promoting evidenceinformed policy and management decisions in healthcare. Non-experimental studies were synthesised thematically, defined as studies reporting quantitative results without both an experimental and control group, or studies reporting qualitative results. This included quasiexperimental studies that do not report quantitative before and after results for primary outcomes related to the effectiveness of research implementation strategies for promoting evidence-informed policy and management decisions in healthcare.

The thematic synthesis was informed by inductive thematic approach for data referring to the factors perceived to be associated with effective strategies and the 
inter-relationship between these factors. The thematic synthesis in this systematic review was based on methods described by Thomas and Harden [43]. Methods involved three stages of analysis: (1) line-byline coding of text, (2) inductive development of descriptive themes similar to those reported in primary studies, (3) analytical themes representing new interpretive constructs undeveloped within studies but apparent between studies once data is synthesised. Data reported in the results section of included studies were reviewed lineby-line and open coded according to meaning and content by the lead investigator (MS). Codes were developed using an inductive approach by the lead investigator (MS) and a second reviewer (TH). Concurrent with data analysis, this entailed constant comparison, ongoing development, and comparison of new codes as each study was coded. Immersing reviewers in the data, reflexive analysis, and peer debriefing techniques were used to ensure methodological rigor throughout the process. Codes and code structure was considered finalised at point of theoretical saturation (when no new concepts emerged from a study). A single researcher (MS) was chosen to conduct the coding in order to embed the interpretation of text within a single immersed individual to act as an instrument of data curation $[44,45]$. Simultaneous axial coding was performed by the lead investigator (MS) and a second reviewer $(\mathrm{TH})$ during the original open coding of data to identify relationships between codes and organise coded data into descriptive themes. Once descriptive themes were developed, the two investigators then organised data across studies into analytical themes using a deductive approach by outlining relationships and interactions between codes across studies. To ensure methodological rigor, a third reviewer (JW) was consulted via group discussion to develop final consensus. The lead author (MS) reviewed any disagreements in descriptive and analytical themes by returning to the original open codes. This cyclical process was repeated until themes were considered to sufficiently describe the factors perceived to be associated with effective strategies and the inter-relationship between these factors.

\section{Results}

\section{Search results}

The search strategy identified a total of 7783 articles, 7716 were identified by the electronic search strategy, 56 from reference checking of identified systematic reviews, 8 from reference checking of included articles, and 3 articles from hand-searching publication lists of prominent authors. Duplicates (3953) were removed using Endnote $(n=3906)$ and Covidence $(n=47)$, leaving 3830 articles for screening (Fig. 1).

Of the 3830 articles, 96 were determined to be potentially eligible for inclusion after title and abstract screening (see Additional file 4 for the full list of 96 articles). The full-text of these 96 articles was then reviewed, with 19 studies ( $n=21$ articles) meeting all relevant criteria for inclusion in this review [9, 27, 46-64]. The most common reason for exclusion upon full-text review was that articles did not examine the effect of a research implementation strategy on decision-making by healthcare policy-makers or managers $(n=22)$.

\section{Characteristics of included studies}

The characteristics of included studies are shown in Table 1. Three experimental studies evaluated the effectiveness of research implementation strategies for promoting evidence-informed policy and management decisions in healthcare systems. Sixteen non-experimental studies described factors perceived to be associated with effective research implementation strategies.

\section{Study design}

Of the 19 included studies, there were two randomised controlled trials (RCTs) [9, 46], one quasi-experimental study [47], four program evaluations [48-51], three implementation evaluations [52-54], three mixed methods [55-57], two case studies [58, 59], one survey evaluation [63], one process evaluation [64], one cohort study [60], and one cross-sectional follow-up survey [61].

\section{Participants and settings}

The largest number of studies were performed in Canada $(n=6)$, followed by the United States of America (USA) $(n=3)$, the United Kingdom (UK) $(n=2)$, Australia $(n=2)$, multi-national $(n=2)$, Burkina Faso $(n=1)$, the Netherlands $(n=1)$, Nigeria $(n=1)$, and Fiji $(n=1)$. Health topics where research implementation took place were varied in context. Decision-makers were typically policymakers, commissioners, chief executive officers (CEOs), program managers, coordinators, directors, administrators, policy analysts, department heads, researchers, change agents, fellows, vice presidents, stakeholders, clinical supervisors, and clinical leaders, from the government, academia, and non-government organisations (NGOs), of varying education and experience.

\section{Research implementation strategies}

There was considerable variation in the research implementation strategies evaluated, see Table 2 for summary description. These strategies included knowledge brokering $[9,49,51,52,57]$, targeted messaging [9, 64], database access $[9,64]$, policy briefs $[46,54,63]$, workshops [47, 54, 56, 60], digital materials [47], fellowship programs $[48,50,59]$, literature reviews/rapid reviews [49, 56, 58, 61], consortium [53], certificate course [54], multi-stakeholder policy dialogue [54], and multifaceted strategies [55]. 


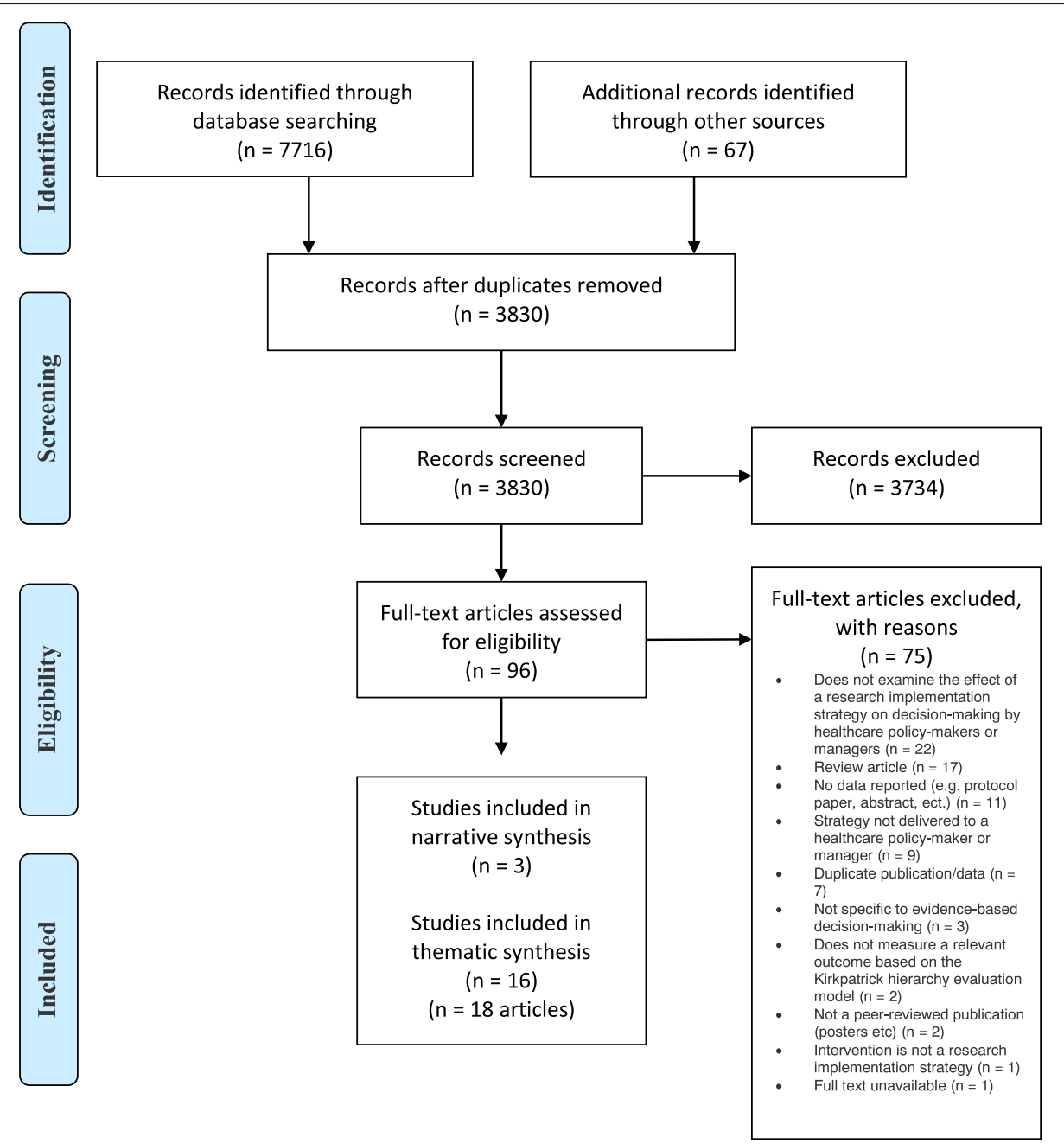

Fig. 1 PRISMA Flow Diagram

\section{Quality/risk of bias \\ Experimental studies}

The potential risk of bias for included experimental studies according to the Cochrane Collaboration tool for assessing risk of bias is presented in Table 3. None of the included experimental studies reported methods for allocation concealment, blinding of participants and personnel, and blinding of outcome assessment [9, 46, 47]. Other potential sources of bias were identified in each of the included experimental studies including (1) inadequate reporting of $p$ values for mixed-effects models, results for hypothesis two, and comparison of health policies and programs (HPP) post-intervention on one study [9], (2) pooling of data from both intervention and control groups limited ability to evaluate the success of the intervention in one study [47], and (3) inadequate reporting of analysis and results in another study [46]. Adequate random sequence generation was reported in two studies [9, 46] but not in one [47]. One study reported complete outcome data [9]; however, large loss to follow-up was identified in two studies $[46,47]$. It was unclear whether risk of selective reporting bias was present for one study [46], as outcomes were not adequately pre-specified in the study. Risk of selective reporting bias was identified for one study that did not report $p$ values for sub-group analysis [9] and another that only reported change scores for outcome measures [47].

\section{Non-experimental studies}

The potential risk of bias for included non-experimental studies according to the Quality Assessment Tool for Observational Cohort and Cross-Sectional Studies from the National Heart, Lung, and Blood Institute, and the Critical Appraisal Skills Program (CASP) Qualitative Checklist is presented in Tables 4 and 5 . 


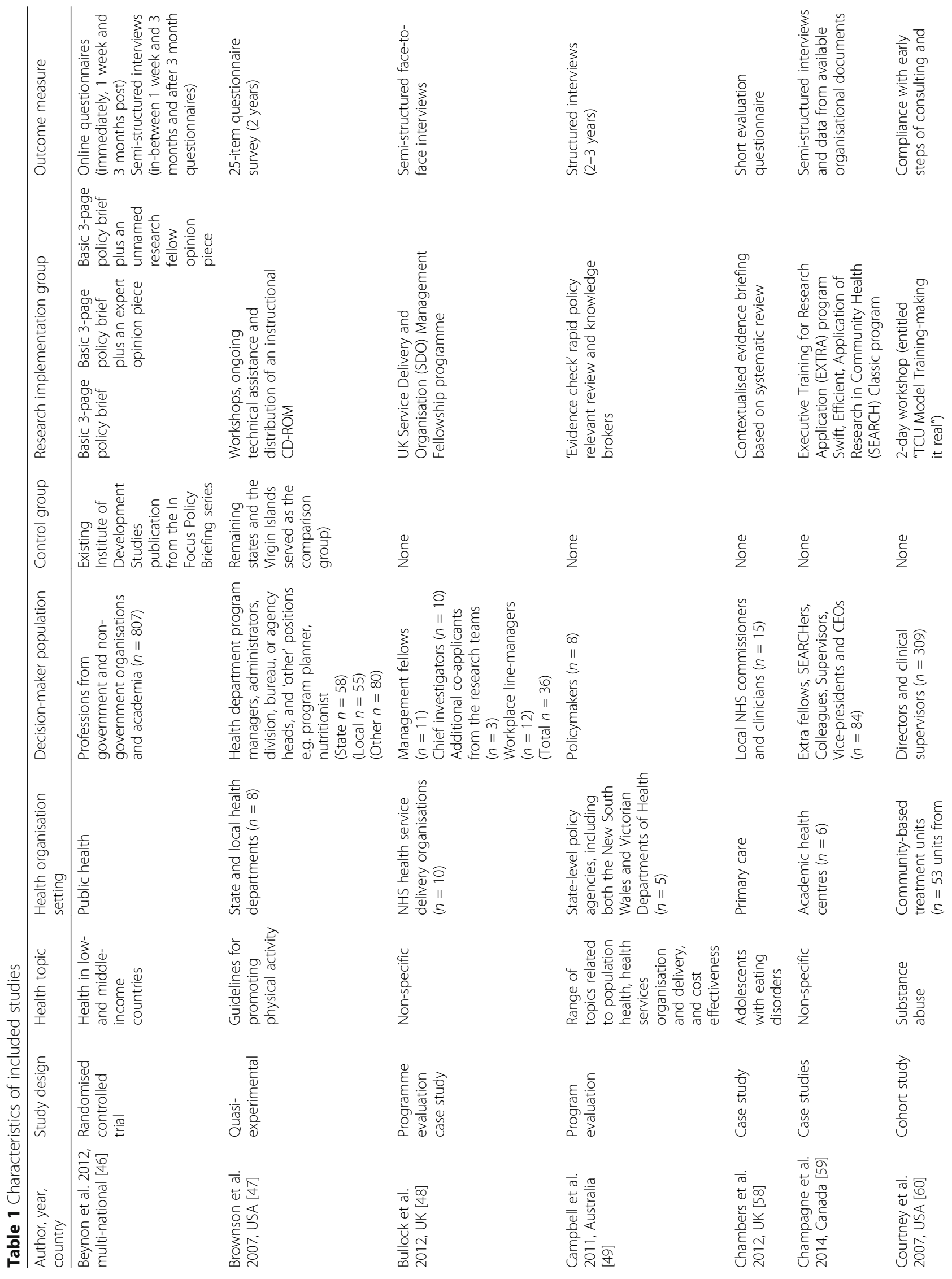




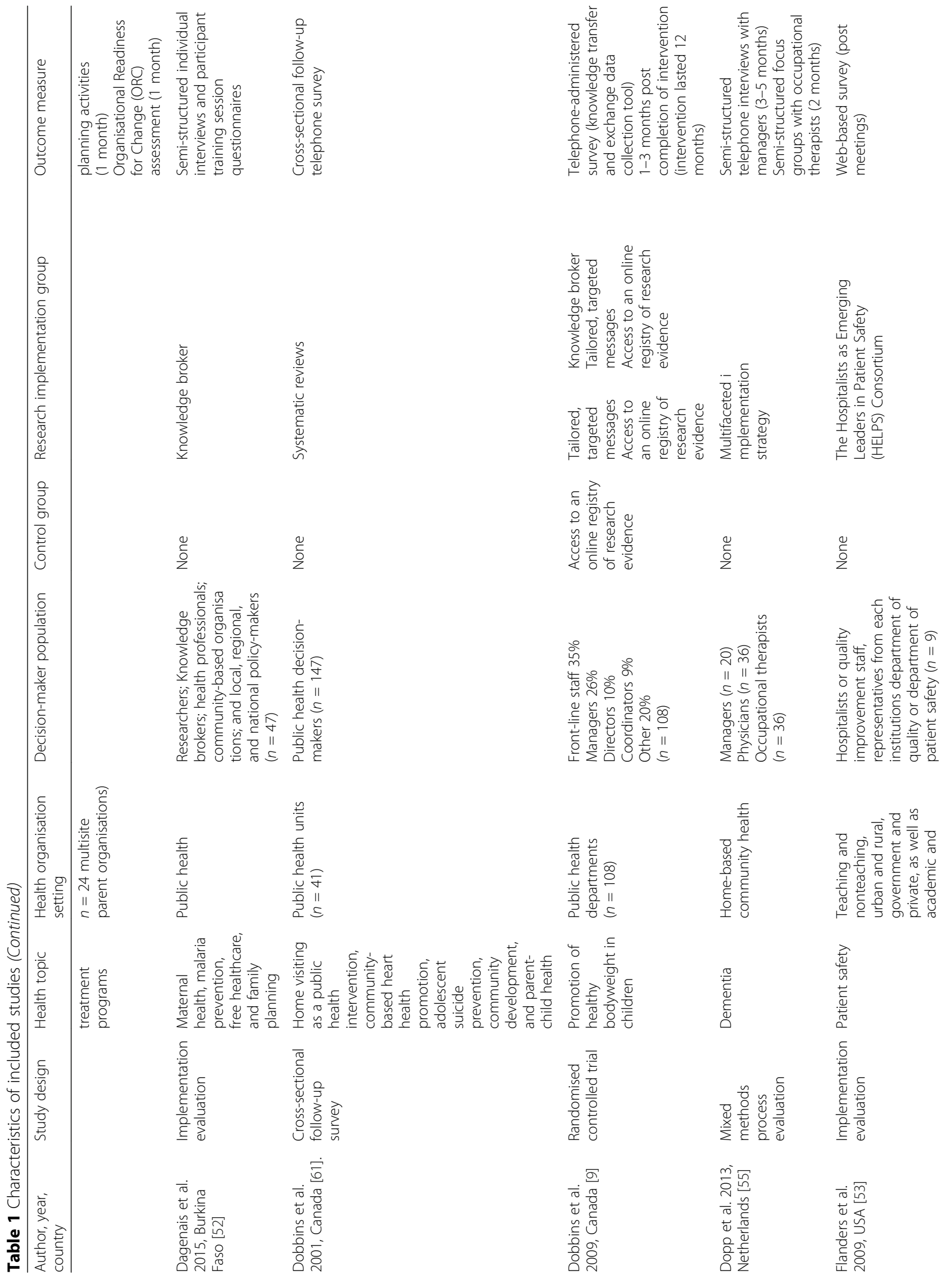




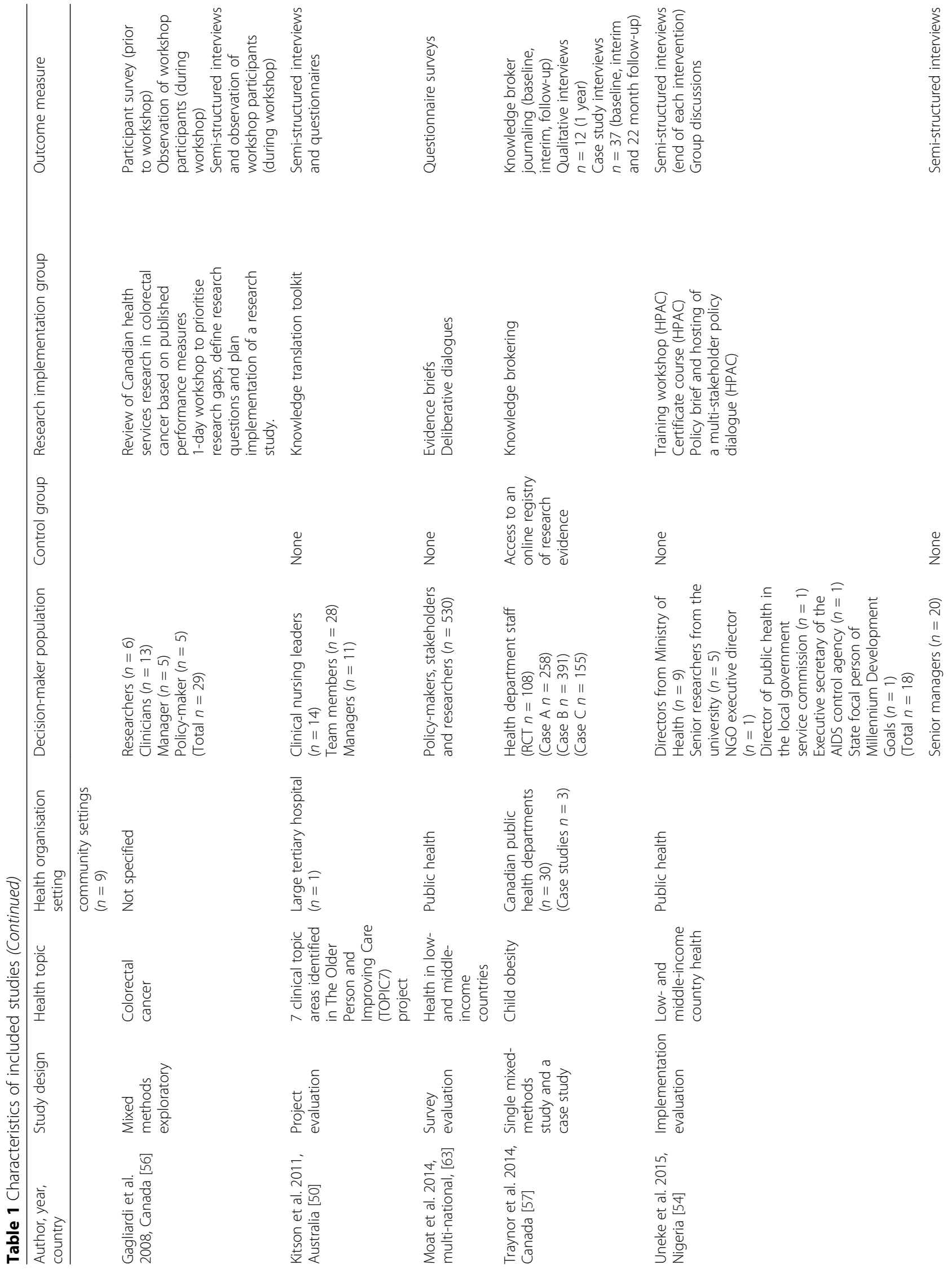




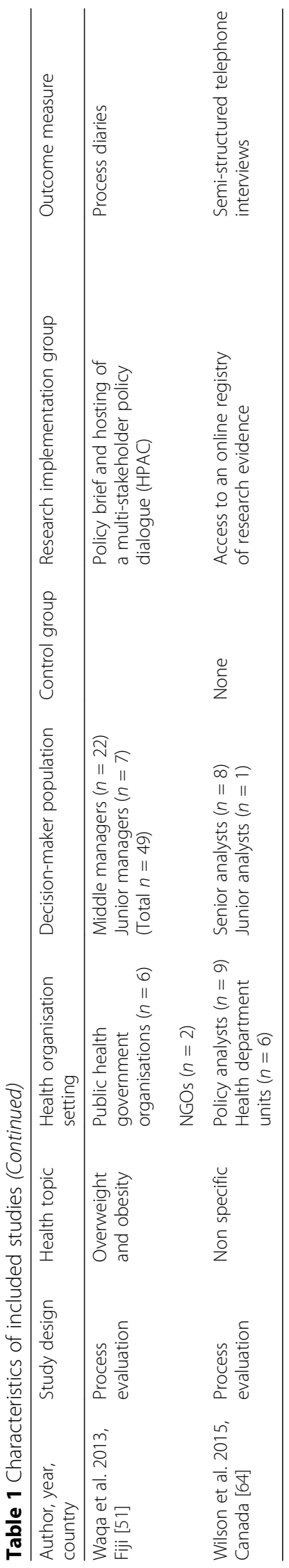


Table 2 Implementation strategy summary description

\begin{tabular}{|c|c|c|c|}
\hline $\begin{array}{l}\text { Study (author, } \\
\text { year) }\end{array}$ & Implementation strategy & Theoretical framework & Summary description \\
\hline \multirow[t]{3}{*}{$\begin{array}{l}\text { Dobbins } \\
\text { 2009, [57, 9] }\end{array}$} & $\begin{array}{l}\text { Access to online registry of } \\
\text { research evidence }\end{array}$ & \multirow[t]{3}{*}{ Dobbins framework } & $\begin{array}{l}\text { Reference offered a link to a short summary and full text } \\
\text { of each review }\end{array}$ \\
\hline & $\begin{array}{l}\text { Tailored, targeted messages } \\
\text { and access to online registry } \\
\text { of research evidence }\end{array}$ & & $\begin{array}{l}\text { Title of systematic review and link to full reference, } \\
\text { including abstract sent via email } \\
\text { Reference offered a link to a short summary and full } \\
\text { text of each review }\end{array}$ \\
\hline & $\begin{array}{l}\text { Knowledge broker, tailored } \\
\text { messages, and access to online } \\
\text { registry of research evidence }\end{array}$ & & $\begin{array}{l}\text { Knowledge brokers ensured relevant evidence was } \\
\text { transferred in useful ways to decision-makers to assist } \\
\text { skills and capacity development for translating evidence } \\
\text { into local healthcare delivery. Activities included regular } \\
\text { electronic and telephone communication, one face-to- } \\
\text { face site visit, and invitation to a workshop. } \\
\text { Title of systematic review and link to full reference, } \\
\text { including abstract sent via email } \\
\text { Reference offered a link to a short summary and full } \\
\text { text of each review }\end{array}$ \\
\hline \multirow{3}{*}{$\begin{array}{l}\text { Beynon } \\
2012,[46]\end{array}$} & Basic 3-page policy brief & \multirow{3}{*}{$\begin{array}{l}\text { A simple theory of } \\
\text { change for a policy } \\
\text { brief }\end{array}$} & Link to policy brief sent via email \\
\hline & $\begin{array}{l}\text { Basic 3-page policy brief } \\
\text { plus an expert opinion piece }\end{array}$ & & $\begin{array}{l}\text { Same basic 3-page policy brief plus an expert opinion } \\
\text { piece credited and written by a sector expert, Lawrence } \\
\text { Haddad. Link to policy brief sent via email }\end{array}$ \\
\hline & $\begin{array}{l}\text { Basic 3-page policy brief plus } \\
\text { an un-credited expert opinion } \\
\text { piece }\end{array}$ & & $\begin{array}{l}\text { Same basic 3-page policy brief and expert opinion piece } \\
\text { but credited to an unnamed research fellow. Link to } \\
\text { policy brief sent via email }\end{array}$ \\
\hline $\begin{array}{l}\text { Brownson } \\
\text { 2007, [47] }\end{array}$ & $\begin{array}{l}\text { Workshops, ongoing technical } \\
\text { assistance, and distribution of } \\
\text { an instructional digital } \\
\text { materials }\end{array}$ & $\begin{array}{l}\text { Framework for a } \\
\text { systematic approach } \\
\text { to promoting effective } \\
\text { physical activity } \\
\text { programs and policies }\end{array}$ & $\begin{array}{l}\text { Workshops included: formal presentations, case study } \\
\text { applications, and 'real-world' examples } \\
\text { Ongoing technical assistance included: strategic planning, } \\
\text { grant writing, tuition waivers, consultation for effective } \\
\text { strategy planning, and dissemination guidance } \\
\text { Digital materials included: additional information, } \\
\text { prominent public health leader interviews, and resource } \\
\text { tools }\end{array}$ \\
\hline $\begin{array}{l}\text { Courtney } \\
2007,[60]\end{array}$ & Workshop & The change book & $\begin{array}{l}\text { Pre-workshop completion of organisational readiness for } \\
\text { change assessment. } \\
\text { Workshop included: conceptual overview presentations, } \\
\text { personalised feedback, comparison with other agencies, } \\
\text { and group work }\end{array}$ \\
\hline
\end{tabular}

Programme evaluation framework (adapted from Kirkpatrick)

Campbell

2011, [49]

Chambers

2012, [58]

Champagne

2014, [59]

Dagenais

2015, [52]
'Evidence check' rapid policy relevant review and knowledge brokers

Contextualised evidence briefing based on systematic review

Executive Training for Research Application (EXTRA) program

Swift, Efficient, Application of Research in Community Health (SEARCH) Classic program

Knowledge broker
Van Kammen et al.'s approach to knowledge brokering

Facilitators of the use of research evidence identified by a systematic review (Innvaer et al. [28])

Knowledge creation logic model

Theoretical models for understanding health behaviour
Practicing managers work within research teams for the duration of a funded project

Pre-meeting commissioning tool completed prior to knowledge broker meetings, which clarified research question. Then a rapid review summary of evidence on policy area is performed

Researcher attended meeting to clarify research question and prepared a concise evidence briefing on policy area

Program included: residency sessions, projects, educational activities, networking, and post-program activities

Program included: modules, inter-module work, and application of knowledge to practice-based projects

Knowledge broker tasks included: liaison, information management and support, partner meetings, developing documentary research strategies, database set-up for relevant information, drafting summary documents, workshops, and developing and monitoring actions plans 
Table $\mathbf{2}$ Implementation strategy summary description (Continued)

\begin{tabular}{|c|c|c|c|}
\hline $\begin{array}{l}\text { Study (author, } \\
\text { year) }\end{array}$ & Implementation strategy & Theoretical framework & Summary description \\
\hline $\begin{array}{l}\text { Dobbins } \\
\text { 2001, [61] }\end{array}$ & & & $\begin{array}{l}\text { Systematic reviews of the effectiveness of public health } \\
\text { interventions disseminated to public health decision-makers }\end{array}$ \\
\hline $\begin{array}{l}\text { Dopp } \\
\text { 2013, [55] }\end{array}$ & $\begin{array}{l}\text { Multifaceted implementation } \\
\text { strategy }\end{array}$ & $\begin{array}{l}\text { The model of Grol and } \\
\text { Wensing }\end{array}$ & $\begin{array}{l}\text { Educational materials, educational meetings, outreach } \\
\text { visits, newsletters, and reminders }\end{array}$ \\
\hline $\begin{array}{l}\text { Flanders } \\
\text { 2009, [53] }\end{array}$ & $\begin{array}{l}\text { The Hospitalists as Emerging } \\
\text { Leaders in Patient Safety } \\
\text { (HELPS) Consortium }\end{array}$ & - & $\begin{array}{l}\text { Meetings on quality improvement methodology and } \\
\text { substantiative patient safety-related topics, and a final } \\
\text { half-day session drawing out learning's and next steps }\end{array}$ \\
\hline $\begin{array}{l}\text { Gagliardi } \\
2008,[56]\end{array}$ & $\begin{array}{l}\text { Comprehensive review and } \\
\text { workshop }\end{array}$ & $\begin{array}{l}\text { Author's conceptual } \\
\text { model of factors } \\
\text { influencing effectiveness } \\
\text { of knowledge exchange }\end{array}$ & $\begin{array}{l}\text { Comprehensive review of Canadian health services } \\
\text { research in colorectal cancer based on published } \\
\text { performance measures and workshop to prioritise } \\
\text { research gaps, define research questions, and plan } \\
\text { implementation of a research study }\end{array}$ \\
\hline $\begin{array}{l}\text { Kitson } \\
2011,[50]\end{array}$ & Knowledge translation toolkit & - & $\begin{array}{l}\text { Team recruitment, clarification, stakeholder engagement, } \\
\text { pre-strategy evaluation, training, support meetings, } \\
\text { communication and feedback, process evaluation, } \\
\text { dissemination (e.g. posters and presentations), future } \\
\text { planning, and program evaluation }\end{array}$ \\
\hline \multirow{2}{*}{$\begin{array}{l}\text { Moat et al. } \\
\text { 2014, multi- } \\
\text { national, [50] }\end{array}$} & Evidence briefs & \multirow{2}{*}{$\begin{array}{l}\text { Theory of planned } \\
\text { behaviour }\end{array}$} & \multirow{2}{*}{$\begin{array}{l}\text { Evidence briefs and deliberative dialogues across a range } \\
\text { of issues and low- and middle-income countries }\end{array}$} \\
\hline & Deliberative dialogues & & \\
\hline $\begin{array}{l}\text { Uneke } \\
\text { 2015, [54] }\end{array}$ & $\begin{array}{l}\text { Training, workshop, certificate } \\
\text { course, policy brief, and } \\
\text { hosting of a multi-stakeholder } \\
\text { policy dialogue }\end{array}$ & - & $\begin{array}{l}\text { Workshop featuring training on the role of research } \\
\text { evidence, preparation of policy briefs, how to organise } \\
\text { and use policy dialogues, and how to set priorities. } \\
\text { Certificate course aimed to foster research capacity, } \\
\text { leadership, enhance capacity for evidence-informed } \\
\text { decision-making, and health policy monitoring/ } \\
\text { evaluation. Policy briefs were produced, and the } \\
\text { multi-stakeholder policy dialogue between key } \\
\text { stakeholders was then held }\end{array}$ \\
\hline $\begin{array}{l}\text { Waqa 2013, } \\
{[51,62]}\end{array}$ & $\begin{array}{l}\text { Knowledge broker capacity } \\
\text { building }\end{array}$ & - & $\begin{array}{l}\text { Knowledge coordinated organisation recruitment, } \\
\text { mapping policy environment, analysed organisational } \\
\text { capacity and support for evidence-informed policymaking, } \\
\text { developed evidence-informed policymaking skills, and } \\
\text { facilitated development of evidence-informed policy briefs }\end{array}$ \\
\hline \multirow{2}{*}{$\begin{array}{l}\text { Wilson et al. } \\
\text { 2015, Canada } \\
\text { [64] }\end{array}$} & $\begin{array}{l}\text { Access to online registry of } \\
\text { research evidence }\end{array}$ & \multirow{2}{*}{$\begin{array}{l}\text { Framework for assessing } \\
\text { country-level efforts to } \\
\text { link research to action }\end{array}$} & $\begin{array}{l}\text { The 'self-serve' evidence service consisted only of database } \\
\text { access }\end{array}$ \\
\hline & $\begin{array}{l}\text { Access to online registry of } \\
\text { research evidence, email } \\
\text { alerts, and full-text availability }\end{array}$ & & $\begin{array}{l}\text { The 'full-serve' evidence service included (1) database access } \\
\text { for research evidence addressing questions about governance, } \\
\text { financial and delivery arrangements within which programs, } \\
\text { services and drugs are provided and about implementation } \\
\text { strategies; (2) monthly email alerts about new additions to } \\
\text { the database; and (3) full-text article availability }\end{array}$ \\
\hline
\end{tabular}

Table 3 Risk of bias of included experimental studies using the Cochrane Collaboration tool for assessing risk of bias

\begin{tabular}{|l|c|c|c|}
\hline & Dobbins et al., 2009, [1] & Beynon et al., 2012, [2] & Brownson et al., 2007, [3] \\
\hline Random sequence generation & $\checkmark$ & $\checkmark$ & $\times$ \\
\hline Allocation concealment & $\times$ & $\times$ & $\times$ \\
\hline Blinding of participants and personnel & $\times$ & $\times$ & $\times$ \\
\hline Blinding of outcome assessment & $\times$ & $\times$ & $\times$ \\
\hline Incomplete outcome data & $\checkmark$ & $?$ & $?$ \\
\hline Selective reporting & $\mathrm{X}$ & $?$ & $\times$ \\
\hline Other sources of bias & $\mathrm{X}$ & $\times$ & $\times$ \\
\hline
\end{tabular}


Table 4 Risk of bias of included non-experimental studies using the Quality Assessment Tool for Observational Cohort and Cross-Sectional Studies

\begin{tabular}{|c|c|c|}
\hline & $\begin{array}{l}\text { Courtney et al., } \\
\text { 2007, [1] }\end{array}$ & $\begin{array}{l}\text { Dobbins et al., } \\
\text { 2001, [2]. }\end{array}$ \\
\hline (1) Was the research question or objective in this paper clearly stated and appropriate? & $\checkmark$ & $\checkmark$ \\
\hline (2) Was the study population clearly specified and defined? & $\checkmark$ & $\checkmark$ \\
\hline (3) Was the participation rate of eligible persons at least $50 \%$ ? & ? & $\checkmark$ \\
\hline $\begin{array}{l}\text { (4) Were all subjects selected or recruited from the same or similar populations (including the same time period)? Were } \\
\text { inclusion and exclusion criteria for being in the study pre-specified and applied uniformly to all participants? }\end{array}$ & $\checkmark$ & $\checkmark$ \\
\hline (5) Was a sample size justification, power description, or variance and effect estimates provided? & $\times$ & $\checkmark$ \\
\hline (6) For the analyses in this paper, were the exposure(s) of interest measured prior to the outcome(s) being measured? & $\checkmark$ & $\checkmark$ \\
\hline $\begin{array}{l}\text { (7) Was the timeframe sufficient so that one could reasonably expect to see an association between exposure and outcomes if } \\
\text { it existed? }\end{array}$ & $\mathbf{n} / \mathbf{a}$ & ? \\
\hline $\begin{array}{l}\text { (8) For exposures that can vary in amount or level, did the study examine different levels of the exposure as related to the } \\
\text { outcome (e.g., categories of exposure, or exposure measured as continuous variable)? }\end{array}$ & $\checkmark$ & $\checkmark$ \\
\hline $\begin{array}{l}\text { (9) Were the exposure measures (independent variables) clearly defined, valid, reliable, and implemented consistently across } \\
\text { all study participants? }\end{array}$ & $\checkmark$ & $\checkmark$ \\
\hline (10) Was the exposure(s) assessed more than once over time? & $\mathbf{n} / \mathbf{a}$ & $\times$ \\
\hline $\begin{array}{l}\text { (11) Were the outcome measures (dependent variables) clearly defined, valid, reliable, and implemented consistently across } \\
\text { all study participants? }\end{array}$ & $\times$ & $\checkmark$ \\
\hline (12) Were the measures of outcome assessors blinded to the exposure status of participants? & $\times$ & $\times$ \\
\hline (13) Was loss to follow-up after baseline $20 \%$ or less? & $\checkmark$ & $\mathbf{n} / \mathbf{a}$ \\
\hline $\begin{array}{l}\text { 14. Were key potential confounding variables measured and adjusted statistically for their impact on the relationship } \\
\text { between exposure(s) and outcome(s)? }\end{array}$ & $\mathbf{n} / \mathbf{a}$ & $\checkmark$ \\
\hline Overall rating (good, fair, or poor)? & Poor & Good \\
\hline
\end{tabular}

n/a not applicable

Narrative synthesis results: effectiveness of research implementation strategies for promoting evidenceinformed policy and management decisions in healthcare Definitive estimates of implementation strategy effect are limited due to the small number of identified studies, and heterogeneity in implementation strategies and reported outcomes. A narrative synthesis of results is described for changes in reaction/attitudes/beliefs, learning, behaviour, and results. See Table 6 for a summary of study results.

\section{Randomised controlled trials}

Interestingly, the policy brief accompanied by an expert opinion piece was thought to improve both level 1 change in reaction/attitudes/beliefs and level 3 behaviour change outcomes. This was referred to as an "authority effect" [46]. Tailored targeted messages also reportedly improved level 3 behaviour change outcomes. However, the addition of a knowledge broker to this strategy may have been detrimental to these outcomes. When organisational research culture was considered, health departments with low research culture may have benefited from the addition of a knowledge broker, although no $p$ values were provided for this finding [9].

\section{Non-randomised studies}

The effect of workshops, ongoing technical assistance, and distribution of instructional digital materials on level 1 change in reaction/attitudes/beliefs outcomes was difficult to determine, as many measures did not change from baseline scores and the direction of change scores was not reported. However, a reduction in perceived support from state legislators for physical activity interventions was reported after the research implementation strategy. All level 2 learning outcomes were reportedly improved, with change scores larger for local than state health department decision-makers in every category except methods in understanding cost. Results were then less clear for level 3 behaviour change outcomes. Only self-reported individual-adapted health behaviour change was thought to have improved [47].

Thematic synthesis results: conceptualisation of factors perceived to be associated with effective strategies and the inter-relationship between these factors

Due to the relative paucity of evidence for effectiveness studies, a thematic synthesis of non-experimental studies was used to explore the factors perceived to be associated with effective strategies and the inter-relationship between these factors. Six broad, interrelated, analytic themes 
Table 5 Risk of bias of included non-experimental studies using the Critical Appraisal Skills Program (CASP) Qualitative Checklist

\begin{tabular}{|c|c|c|c|c|c|c|c|c|c|c|c|c|c|c|}
\hline & $\begin{array}{l}\text { Bullock } \\
\text { et al., } \\
2012, \\
{[1]}\end{array}$ & $\begin{array}{l}\text { Campbell } \\
\text { et al., } \\
\text { 2011, [2] }\end{array}$ & $\begin{array}{l}\text { Chambers } \\
\text { el al., } \\
2012,[3]\end{array}$ & $\begin{array}{l}\text { Champagne } \\
\text { et al., 2014, } \\
\text { [4] }\end{array}$ & $\begin{array}{l}\text { Dagenais } \\
\text { et al., } \\
2015 \text {, } \\
{[5]}\end{array}$ & $\begin{array}{l}\text { Dopp } \\
\text { et al., } \\
2013 \text {, } \\
{[6]}\end{array}$ & $\begin{array}{l}\text { Flanders } \\
\text { et al., } \\
\text { 2009, [7] }\end{array}$ & $\begin{array}{l}\text { Gagliardi } \\
\text { et al., } \\
2008,[8]\end{array}$ & $\begin{array}{l}\text { Kitson } \\
\text { et al., } \\
2011, \\
{[9]}\end{array}$ & $\begin{array}{l}\text { Moat } \\
\text { et al., } \\
2014 \text {, } \\
{[10]}\end{array}$ & $\begin{array}{l}\text { Traynor } \\
\text { et al., } \\
\text { 2014, } \\
\text { [11] }\end{array}$ & $\begin{array}{l}\text { Uneke } \\
\text { et al., } \\
2015, \\
{[12]}\end{array}$ & $\begin{array}{l}\text { Waqa } \\
\text { et al., } \\
2013, \\
{[13,} \\
14]\end{array}$ & $\begin{array}{l}\text { Wilson } \\
\text { et al., } \\
2015, \\
{[15]}\end{array}$ \\
\hline $\begin{array}{l}\text { (1) Was there } \\
\text { a clear } \\
\text { statement of } \\
\text { the aims of the } \\
\text { research? }\end{array}$ & $\checkmark$ & $x$ & $\checkmark$ & $\checkmark$ & $\checkmark$ & $\checkmark$ & $\checkmark$ & $\checkmark$ & $\checkmark$ & $\checkmark$ & $\checkmark$ & $\checkmark$ & $\checkmark$ & $\checkmark$ \\
\hline $\begin{array}{l}\text { (2) Is a } \\
\text { qualitative } \\
\text { methodology } \\
\text { appropriate? }\end{array}$ & $\checkmark$ & $x$ & $?$ & $\checkmark$ & $\checkmark$ & $\checkmark$ & $?$ & $\checkmark$ & $\checkmark$ & $\checkmark$ & $\checkmark$ & $\checkmark$ & $\checkmark$ & $\checkmark$ \\
\hline $\begin{array}{l}\text { (3) Was the } \\
\text { research } \\
\text { design } \\
\text { appropriate to } \\
\text { address the } \\
\text { aims of the } \\
\text { research? }\end{array}$ & $\checkmark$ & $?$ & ? & $?$ & $?$ & $\checkmark$ & $?$ & $\checkmark$ & $\checkmark$ & $\checkmark$ & $\checkmark$ & $\checkmark$ & $\times$ & $\checkmark$ \\
\hline $\begin{array}{l}\text { (4) Was the } \\
\text { recruitment } \\
\text { strategy } \\
\text { appropriate to } \\
\text { the aims of the } \\
\text { research? }\end{array}$ & $\checkmark$ & $x$ & $\times$ & $?$ & $\times$ & $\checkmark$ & $?$ & $\checkmark$ & $?$ & $?$ & $\checkmark$ & $?$ & $\checkmark$ & $\checkmark$ \\
\hline $\begin{array}{l}\text { (5) Was the } \\
\text { data collected } \\
\text { in a way that } \\
\text { addressed the } \\
\text { research } \\
\text { issue? }\end{array}$ & ? & $x$ & $?$ & $\checkmark$ & $?$ & $\times$ & ? & $\checkmark$ & $\checkmark$ & $?$ & $\checkmark$ & $\checkmark$ & $?$ & $\checkmark$ \\
\hline $\begin{array}{l}\text { (6) Has the } \\
\text { relationship } \\
\text { between } \\
\text { researcher } \\
\text { and } \\
\text { participants } \\
\text { been } \\
\text { adequately } \\
\text { considered? }\end{array}$ & $\times$ & $x$ & $x$ & $x$ & $\times$ & $\checkmark$ & $x$ & $x$ & $\times$ & $\times$ & $\times$ & $\times$ & $x$ & $\times$ \\
\hline $\begin{array}{l}\text { (7) Have the } \\
\text { ethical issues } \\
\text { been taken } \\
\text { into } \\
\text { consideration? }\end{array}$ & ? & $x$ & $\times$ & $\checkmark$ & $?$ & $\checkmark$ & $x$ & $\checkmark$ & $?$ & $x$ & $\checkmark$ & $?$ & $?$ & $\checkmark$ \\
\hline $\begin{array}{l}\text { (8) Was the } \\
\text { data analysis } \\
\text { sufficiently } \\
\text { rigorous? }\end{array}$ & $\times$ & $\times$ & $\times$ & $\checkmark$ & $x$ & $\checkmark$ & ? & $\checkmark$ & $\checkmark$ & ? & $\checkmark$ & $\checkmark$ & $?$ & $\checkmark$ \\
\hline $\begin{array}{l}\text { (9) Is there a } \\
\text { clear } \\
\text { statement of } \\
\text { findings? }\end{array}$ & $\checkmark$ & $x$ & $\checkmark$ & $\checkmark$ & $\checkmark$ & $\checkmark$ & ? & $\checkmark$ & $\checkmark$ & ? & $\checkmark$ & $\checkmark$ & ? & $\checkmark$ \\
\hline $\begin{array}{l}\text { (10) Is the } \\
\text { research } \\
\text { valuable? }\end{array}$ & $\checkmark$ & $x$ & $\checkmark$ & $?$ & $\checkmark$ & $\checkmark$ & $?$ & $\checkmark$ & $?$ & $?$ & $\checkmark$ & $\checkmark$ & $?$ & $\checkmark$ \\
\hline
\end{tabular}

emerged from the thematic synthesis of data captured in this review (Fig. 2). We developed a conceptualisation of how these themes interrelated from data captured both within and across studies. Some of these analytic themes were specifically mentioned in individual papers, but none of the papers included in this review identified all, nor developed a conceptualisation of how they interrelated. The six analytic themes were conceptualised as having a unidirectional, hierarchal flow from (1) establishing an imperative for practice change, (2) building trust between implementation stakeholders, (3) developing a shared vision, and (4) actioning change mechanisms. These were underpinned by (5) employment of effective communication strategies and (6) provision of resources to support change.

\section{Establish imperative}

Organisations and individuals were driven to implement research into practice when there was an imperative for 
Table 6 Summary of study results

\begin{tabular}{|c|c|c|c|c|}
\hline $\begin{array}{l}\text { Study (author, } \\
\text { year) }\end{array}$ & $\begin{array}{l}\text { Implementation } \\
\text { strategy }\end{array}$ & $\begin{array}{l}\text { Level 1: change in } \\
\text { reaction/attitudes/beliefs }\end{array}$ & Level 2: learning & Level 3: behaviour \\
\hline \multicolumn{5}{|c|}{ Randomised controlled trial } \\
\hline \multirow[t]{3}{*}{$\begin{array}{l}\text { Beynon } 2012 \\
{[46]}\end{array}$} & $\begin{array}{l}\text { Basic 3-page } \\
\text { policy brief }\end{array}$ & $\begin{array}{l}\text { High-quality ratings } \\
\text { Opinion about evidence } \\
\text { strength or intervention } \\
\text { effectiveness varies by } \\
\text { health topic }\end{array}$ & - & $\begin{array}{l}\text { Less likely to source other information and } \\
\text { research related to the topic than control }\end{array}$ \\
\hline & $\begin{array}{l}\text { Basic 3-page } \\
\text { policy brief plus } \\
\text { an expert opinion } \\
\text { piece }\end{array}$ & $\begin{array}{l}\text { High-quality rating } \\
\text { Opinion about evidence } \\
\text { strength or intervention } \\
\text { effectiveness varies by } \\
\text { health topic. } \\
\text { Increased intention to send } \\
\text { policy brief to someone else } \\
\text { and tell someone about key } \\
\text { messages }\end{array}$ & - & $\begin{array}{l}\text { Less likely to source other information and } \\
\text { research related to the topic than control. } \\
\text { Trend towards intentions persisting to } \\
\text { actions. } \\
\text { More likely to send policy brief to someone } \\
\text { else }\end{array}$ \\
\hline & $\begin{array}{l}\text { Basic 3-page } \\
\text { policy brief plus an } \\
\text { un-credited expert } \\
\text { opinion piece }\end{array}$ & $\begin{array}{l}\text { High-quality rating } \\
\text { Opinion about evidence } \\
\text { strength or intervention } \\
\text { effectiveness varies by } \\
\text { health topic }\end{array}$ & - & $\begin{array}{l}\text { Less likely to source other information and } \\
\text { research related to the topic than control }\end{array}$ \\
\hline \multirow[t]{2}{*}{$\begin{array}{l}\text { Dobbins } \\
2009[9]\end{array}$} & $\begin{array}{l}\text { Tailored, targeted } \\
\text { messages }\end{array}$ & - & - & $\begin{array}{l}\text { Improved use of public health policies and } \\
\text { programs compared to control }\end{array}$ \\
\hline & $\begin{array}{l}\text { Tailored, targeted } \\
\text { messages plus a } \\
\text { knowledge broker }\end{array}$ & - & - & $\begin{array}{l}\text { Addition of knowledge broker potentially } \\
\text { reduced use of public health policies and } \\
\text { programs. However, improvements may } \\
\text { have occurred in organisations with low } \\
\text { research culture }\end{array}$ \\
\hline \multicolumn{5}{|c|}{ Non-randomised controlled trial } \\
\hline $\begin{array}{l}\text { Brownson } \\
2007[47]\end{array}$ & $\begin{array}{l}\text { Workshops, } \\
\text { ongoing technical } \\
\text { assistance, and } \\
\text { digital resources }\end{array}$ & $\begin{array}{l}\text { Change in whether heard } \\
\text { of recommendations and } \\
\text { attended training. } \\
\text { Less likely to report state } \\
\text { legislators were supportive } \\
\text { of physical activity interventions. } \\
\text { No change in other outcomes } \\
\text { from baseline }\end{array}$ & $\begin{array}{l}\text { All knowledge and skill } \\
\text { measurements improved. } \\
\text { Change larger for local than } \\
\text { state health department } \\
\text { decision-makers in every } \\
\text { category except methods } \\
\text { in understanding cost. } \\
\text { The largest change related to } \\
\text { attitudes }\end{array}$ & $\begin{array}{l}\text { Improvement in self-reported individual } \\
\text { adapted health behaviour change. } \\
\text { No difference in other behaviour change } \\
\text { outcomes }\end{array}$ \\
\hline
\end{tabular}

practice change. Decision-makers wanted to know why change was important to them, and their organisation and or community. Imperatives were seen as drivers of motivation for change to take place and were evident both internal to the decision-maker (personal gain) and external to the decision-makers (organisational and societal gain).

Personal gain Individuals were motivated to participate in research implementation projects where they could derive personal gain $[48,50,56]$. Involvement in research was viewed as an opportunity rather than an obligation [56]. This was particularly evident in one study by Kitson et al. where all nursing leaders unanimously agreed the potential benefit of supported, experiential learning was substantial, with 13 of 14 committing to leading further interdisciplinary, cross-functional projects [50].

Organisational and societal gain Decision-makers supported research implementation efforts when they aligned to an organisational agenda or an area where societal health needs were identified $[48,50,53,55,59,64]$. Practice change was supported if it was deemed important by decision-makers and aligned with organisational priorities, where knowledge exchange was impeded if changes had questionable relevance to the workplace $[48,53,64]$. Individuals reported motivation to commit to projects they felt would address community needs. For example, in one study, nursing leaders identified their passion for health topics as a reason to volunteer in a practice change process [50]. In another study, managers were supportive 


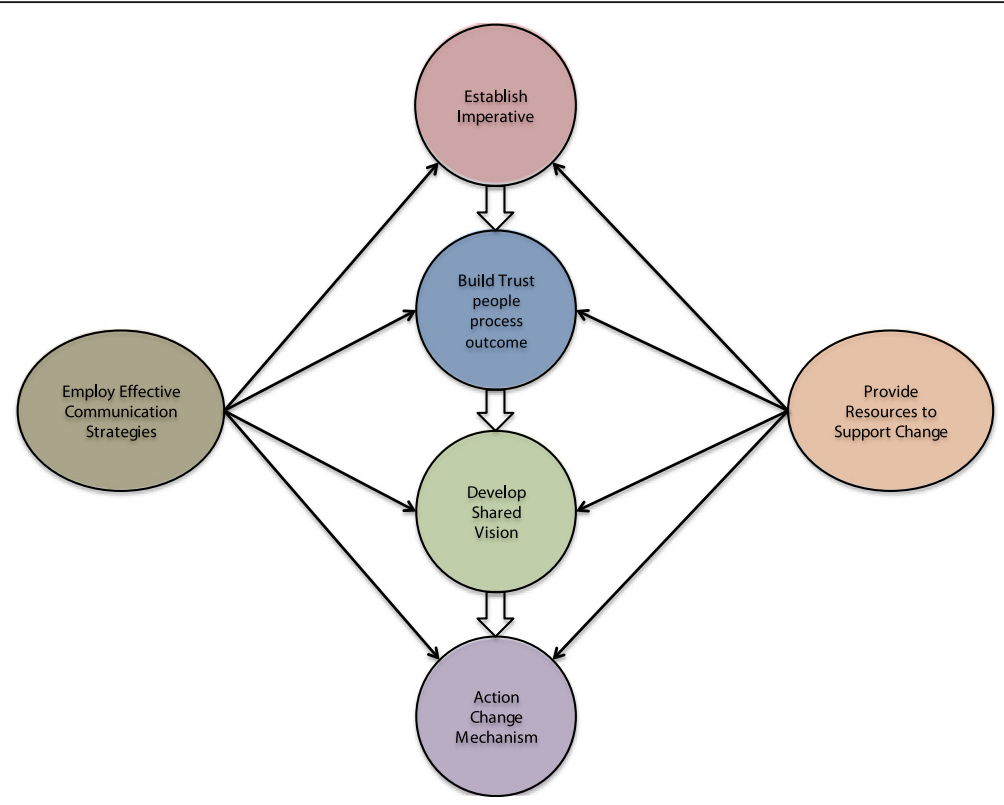

Fig. 2 Conceptualisation of Inter-related themes (analytic themes) associated with effective strategies and the inter-relationship between these factors

of practice change to improve care of people with dementia, as they thought this would benefit the population [55].

\section{Build trust}

Relationships, leadership authority, and governance constituted the development of trust between stakeholder groups.

Relationships The importance of trusting relationships between managers, researchers, change agents, and staff was emphasised in a number of studies [48, 50, 54, 59, 64]. Developing new relationships through collaborative networking and constant contact reportedly addressed mutual mistrust between policy-makers and the researchers, and engaged others to change practice [54,59]. Bullock et al. described how pre-existing personal and professional relationships might facilitate implementation strategy success through utilising organisational knowledge and identifying workplace "gatekeepers" to engagement with. In the same study, no real link between healthcare managers and academic resources was derived from fellows that were only weakly connected to healthcare organisations [48].

Leadership authority The leadership authority of those involved in research implementation influenced the development of trust between key stakeholders [50, 52, 55, 59, 61]. Dagenais et al. found recommendations and information was valued if credited from researchers and change agents whose input was trusted [52]. The perception that individuals with senior organisational roles reduce perceived risk and resistance to change was supported by Dobbins et al., who reported that seniority of individuals is a predictor of systematic review use in decision-making [50, 59, 61]. However, professional seniority should be related to the research implementation context, as the perceived lack of knowledge in content area was a barrier to providing managerial support [55].

Governance A number of studies expressed the importance of consistent and sustained executive support in order to maintain project momentum $[48,50,52,53,59,64]$. In the study by Kitson et al, individuals expressed concern and anxiety around reputational risk if consistent organisation support was not provided [50]. Organisational capacity was enhanced with strong management support and policies [57]. Uneke et al. identified good stewardship in the form of governance to provide accountability and protection for individuals and organisations in their study. Participants in this study unanimously identified the need for performance measurement mechanisms for the health policy advisory committee to promote sustainability and independent evidence to policy advice [54]. Bullock et al. found that managers view knowledge exchange in a transaction manner and are keen to know and use project results as soon as possible. However, researchers and change agents may not wish to apply results due to the phase of the project [48]. This highlighted the importance of governance systems to support confidentiality and limiting the release of project results before stakeholders are confident of findings. 


\section{Develop shared vision}

A shared vision for desired change and outcomes can be built around common goal through improving understanding, influencing behaviour change, and working with the characteristics of organisations.

Stakeholder understanding Improving the understanding of research implementation was considered a precursor to building shared vision [50, 52, 55, 56]. Policy-makers reported lack of time prevented them from performing an evidence review and desired experientially tailored information, education, and avoidance of technical language to improve understanding $[52,55,58]$. It was perceived that lack of clarity limited project outcomes in the study by Gagliardi et al., which emphasised the need for simple processes [56]. When challenges arose in Kitson et al, ensuring all participants understood their role from implementation outset was suggested as a process improvement [50].

Influence change Knowledge brokers in Campbell et al. were able to elicit well-defined research questions if they were open, honest, and frank in their approach to policymakers. Policy-makers felt that knowledge brokering was more useful for shaping parameters, scope, budget, and format of projects, which provides guidance for decisionmaking rather than being prescriptive [49]. However, conclusive recommendations that aim for a consensus are viewed favourably by policy-makers, which means a balance between providing guidance without being too prescriptive, must be achieved [63]. Interactive strategies may allow change agents to gain better understanding of evidence in organisational decisions and guide attitudes towards evidence-informed decision-making. Champagne et al. observed fellows participating in this interactive, social process, and Dagenais et al. reported practical exercises and interactive discussions were appreciated by knowledge brokers in their own training $[52,59]$. Another study reported barriers in work practice challenges being viewed as criticism; despite this, organisation staff valued leaders' ability to inspire a shared vision and identified 'challenging processes' as the most important leadership practice [50].

Characteristics of organisation Context-specific organisational characteristics such as team dynamics, change culture, and individual personalities can influence the effectiveness of research implementation strategies [50, 53, 56, 59]. Important factors in Flanders et al. were clear lines of authority in collaborative and effective multidisciplinary teams. Organisation readiness for change was perceived as both a barrier and a facilitator to research implementation but higher staff consensus was associated with higher engagement in organisational change [60]. Strategies in Dobbins et al. were thought to be more effective if they were implemented in organisations with learning culture and practices, or facilitated an organisational learning culture themselves, where Flanders et al. reported solutions to hospital safety problems often created more work or change from long-standing practices, which proved a barrier to overcome [53, 61]. Individual resistance to change in the form of process concerns led to higher levels of dissatisfaction [50].

\section{Provide resources to support change}

Individuals were conscious of the need for implementation strategies to be adequately resourced [48-50, 55, 56, $58,59,61]$. There was anxiety in the study by Döpp et al. around promoting research implementation programs, due to the fear of receiving more referrals than could be handled with current resourcing [55]. Managers mention service pressures as a major barrier in changing practice, with implementation research involvement dependent on workload and other professional commitments [50, 56]. Lack of time prevented evidence reviews being performed, and varied access to human resources such as librarians were also identified as barriers [58, 59]. Policy-makers and managers appreciated links to expert researchers, especially those who had infrequent or irregular contact with the academic sector previously [49]. Managers typically viewed engagement with research implementation as a transactional idea, wanting funding for time release (beyond salary costs), while researchers and others from the academic sector consider knowledge exchange inherently valuable [48]. Vulnerability around leadership skills and knowledge in the study by Kitson et al. exposed the importance of training, education, and professional development opportunities. Ongoing training in critical appraisal of research literature was viewed as a predictor of whether systematic reviews influenced program planning [61].

\section{Employ effective communication strategies}

Studies and study participants expressed different preferences for the format and mode of contact for implementation strategies $[48,51,52,55,56,59,64]$. Face to face contact was preferred by the majority of participants in the study by Waqa et al. and was useful in acquiring and accessing relevant data or literature to inform the writing of policy briefs [51]. Telephone calls were perceived as successful in Döpp et al. because they increased involvement and opportunity to ask questions [55]. Electronic communication formats in the study by Bullock et al. provided examples of evidence-based knowledge transfer from academic settings to the clinical setting. Fellows spent time reading literature at the university and would then send that information to the clinical workplace in an email, while managers stated that the availability of website information positively influenced its use [48]. Regular contact in the form of reminders encouraged actions, with the study by 
Dagenais et al. finding lack of ongoing, regular contact with knowledge brokers in the field limitated research implementation programs [52].

\section{Action change mechanism}

Reviewers interpreted the domains (analytical themes) representing a model of implementation strategy success to lead to a change mechanism. Change mechanisms refer to the actions taken by study participants to implement research into practice. Studies did not explicitly measure the change mechanisms that lead to the implementation of research into practice. Instead, implicit measurements of change mechanisms were reported such as knowledge gain and intention to act measures.

\section{Discussion}

This review found that there are numerous implementation strategies that can be utilised to promote evidenceinformed policy and management decisions in healthcare. These relate to the 'authority effect' from a simple low-cost policy brief and knowledge improvement from a complex multifaceted workshop with ongoing technical assistance and distribution of instructional digital materials $[46,47]$. The resource intensity of these strategies was relatively low. It was evident that providing more resource-intensive strategies is not always better than less, as the addition of a knowledge broker to a tailored targeted messaging strategy was less effective than the messages alone [9]. Due to the paucity of studies evaluating the effectiveness of implementation strategies, understanding why some implementation strategies succeed where others fail in different contexts is important for future strategy design. The thematic synthesis of the wider non-effectiveness literature included in our review has lead us to develop a model of implementation strategy design that may action a change mechanism for evidence-informed policy and management decisions in healthcare [48-61, 63, 64].

Our findings were concomitant with change management theories. The conceptual model of how themes interrelated both within and across studies includes similar stages to 'Kotter's 8 Step Change Model' [65]. Leadership behaviours are commonly cited as organisational change drivers due to the formal power and authority that leaders have within organisations [66-68]. This supports the 'authority effect' described in Beynon et al. and the value decision-makers placed on information credited to experts they trust [46]. Authoritative messages are considered a key component of an effective policy brief, and therefore, organisations should consider partnering with authoritative institutions, research groups, or individuals to augment the legitimacy of their message when producing policy briefs [69]. Change management research proposes change-related training improves understanding, knowledge, and skills to embed a change vision at a group level [70-72]. The results of our review support this view that providing adequate training resources to decision-makers can improve understanding, knowledge, and skills, leading to desired change. The results of our thematic synthesis appear to support knowledge broker strategies in theory. Multicomponent research implementation strategies are thought to have greater effects than simple strategies [73, 74]. However, the addition of knowledge brokers to a tailored targeted messaging research implementation strategy in Dobbins et al. was less effective than the messages alone [9]. This may indicate that in some cases, simple research implementation strategies may be more effective than complex, multi-component ones. Further development of strategies is needed to ensure that a number of different implementation options are available, which can be tailored to individual health contexts. A previous review by LaRocca et al. supports this finding, asserting that in some cases, complex strategies may diminish key messages and reduce understanding of information presented [10]. Further, the knowledge broker strategy in Dobbins et al. had little or no engagement from $30 \%$ of participants allocated to this group, emphasising the importance of tailoring strategy complexity and intensity to organisational need.

This systematic review was limited both in the quantity and quality of studies that met inclusion criteria. Previous reviews have been similarly limited in the paucity of high-quality research evaluating the effectiveness of research implementation strategies in the review context area $[10$, $29,32,75]$. The limited number of retrieved experimental, quantitatively evaluated effectiveness studies, means the results of this review were mostly based on nonexperimental qualitative data without an evaluation of effectiveness. Non-blinding of participants could have biased qualitative responses. Participants could have felt pressured to respond in a positive way if they did not wish to lose previously provided implementation resources, and responses could vary depending on the implementation context and what changes were being made, for example, if additional resources were being implemented to fill an existing evidence-to-practice gap, versus the disinvestment of resources due to a lack of supportive evidence. Despite these limitations, we believe our comprehensive search strategy retrieved a relatively complete identification of studies in the field of research. A previous Cochrane review in the same implementation context area recently identified only one study (also captured in our review) using their search strategy and inclusion criteria [33, 76]. A meta-analysis was unable to be performed due to the limited amount of studies and high levels of heterogeneity in study approaches, as such, the results of this synthesis should be interpreted with caution. However, synthesising 
data narratively and thematically allowed this review to examine not only the effectiveness of research implementation strategies in the context area but also the mechanisms behind inter-relating factors perceived to be associated with effective strategies. Since our original search strategy, we have been unable to identify additional full-texts from the 11 titles excluded due to no data reporting (e.g. protocol, abstract). However, the Developing and Evaluating Communication strategies to support Informed Decisions and practice based on Evidence (DECIDE) project has since developed a number of tools to improve the dissemination of evidence-based recommendations [77]. In addition, support for the relationship development, face to face interaction, and focus on organisational climates themes in our conceptual model is supported by the full version [78] of an excluded summary article [79], identified after the original search strategy.

Studies measured behaviour changes considered on the third level of the Kirkpatrick Hierarchy but did not measure whether those behaviour changes led to their intended improved societal outcomes (level 4, Kirkpatrick Hierarchy). Future research should also evaluate changes in health and organisational outcomes. The conceptualisation of factors perceived to be associated with effective strategies and the inter-relationship between these factors should be interpreted with caution as it was based on low levels of evidence according to the National Health and Medical Research Council (NHMRC) of Australia designations [80]. Therefore, there is a need for the association between these factors and effective strategies to be rigorously evaluated. Further conceptualisation of how to evaluate research implementation strategies should consider how to include health and organisation outcome measures to better understand how improved evidence-informed decision-making can lead to greater societal benefits. Future research should aim to improve the relatively low number of high-quality randomised controlled trials evaluating the effectiveness of research implementation strategies for promoting evidence-informed policy and management decisions in healthcare. This might allow formal meta-analysis to be performed, providing indications of what research implementation strategies are effective in which context.

\section{Conclusions}

Evidence is developing to support the use of research implementation strategies for promoting evidenceinformed policy and management decisions in healthcare. A number of inter-relating factors were thought to influence the effectiveness of strategies through establishing an imperative for change, building trust, developing a shared vision, and action change mechanisms.
Employing effective communication strategies and providing resources to support change underpin these factors, which should inform the design of future implementation strategies.

\section{Additional files}

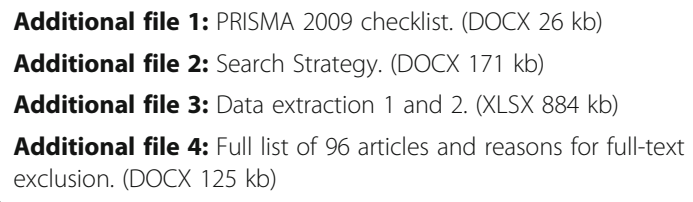

\section{Abbreviations}

CEO: Chief executive officer; NGO: Non-government organisation; NHMRC: National Health and Medical Research Council; PRISMA: Preferred Reporting Items for Systematic Reviews and Meta-Analysis; RCT: Randomised controlled trial; UK: United Kingdom; USA: United States of America

\section{Acknowledgements}

Authors' would like to acknowledge the expertise provided by Jenni White and the support provided by the Monash University library staff and the Monash University and Monash Health Allied Health Research Unit.

\section{Funding}

No funding

Availability of data and materials

Data are available from the corresponding author on reasonable request.

\section{Authors' contributions}

MS was responsible for the conception, organisation and completion of this systematic review. MS developed the research question and search strategy, conducted the search, screened the retrieved studies, extracted the data, performed the analysis and quality appraisal, and prepared the manuscript. $K A B$ was responsible for the oversight and management of the review. KAB contributed to the development of the inclusion and exclusion criteria; resolved screening, quality, and data extraction discrepancies between reviewers; and assisted with the manuscript preparation. ES also was responsible for the oversight and helped develop the final research question and inclusion criteria. ES assisted with selecting and using the quality appraisal tool, developing the data extraction tool, and preparing the manuscript. $\mathrm{RH}$ and $\mathrm{HL}$ were responsible for performing independent screening of identified studies and deciding upon inclusion or exclusion from the review. $\mathrm{RH}$ and $\mathrm{HL}$ also performed independent quality appraisal and data extraction for half of the included studies and contributed to the manuscript preparation. TH was responsible for the oversight and management of the review, assisted with data analysis and interpretation, and contributed to the manuscript preparation. All authors read and approved the final manuscript.

\section{Authors' information}

Mitchell Sarkies is a Physiotherapist from Melbourne, Victoria, Australia, with an interest in translating research into practice. He is currently a Ph.D. candidate at Monash University.

Ethics approval and consent to participate Not applicable.

Consent for publication Not applicable.

Competing interests

The authors declare that they have no competing interests. 


\section{Publisher's Note}

Springer Nature remains neutral with regard to jurisdictional claims in published maps and institutional affiliations.

\section{Author details \\ 'Kingston Centre, Monash University and Monash Health Allied Health Research Unit, 400 Warrigal Road, Heatherton, VIC 3202, Australia. ${ }^{2}$ Monash University Department of Community Emergency Health and Paramedic Practice, Building H McMahons Road, Frankston, VIC 3199, Australia.}

Received: 20 February 2017 Accepted: 1 November 2017 Published online: 14 November 2017

\section{References}

1. Orton L, Lloyd-Williams F, Taylor-Robinson D, O'Flaherty M, Capewell S. The use of research evidence in public health decision making processes: systematic review. PLoS One. 2011;6(7):e21704

2. Ciliska D, Dobbins $M$, Thomas $H$. Using systematic reviews in health services, Reviewing research evidence for nursing practice: systematic reviews; 2007. p. 243-53.

3. Mosadeghrad AM. Factors influencing healthcare service quality. Int J Health Policy Manag. 2014:3(2):77-89. 10.15171/ijhpm.2014.65.

4. Brownson RC, Fielding JE, Maylahn CM. Evidence-based public health: a fundamental concept for public health practice. Annu Rev Public Health. 2009;30:175-201

5. Jernberg $T$, Johanson $P$, Held C, Svennblad B, Lindback J, Wallentin L. Association between adoption of evidence-based treatment and survival for patients with ST-elevation myocardial infarction. JAMA. 2011;305 https://doi. org/10.1001/jama.2011.522

6. Davis $D$, Davis $M E$, Jadad A, Perrier $L$, Rath $D$, Ryan $D$, et al. The case for knowledge translation: shortening the journey from evidence to effect. BMJ. 2003;327(7405):33-5

7. Madon T, Hofman K, Kupfer L, Glass R. Public health: implementation science. Science. 2007;318 https://doi.org/10.1126/science.1150009.

8. Chalmers I. If evidence-informed policy works in practice, does it matter if it doesn't work in theory? Evid Policy. 2005;1 https://doi.org/10.1332/ 1744264053730806.

9. Dobbins M, Hanna SE, Ciliska D, Manske S, Cameron R, Mercer SL, et al. A randomized controlled trial evaluating the impact of knowledge translation and exchange strategies. Implement Sci. 2009;4(1):1-16. https://doi.org/10. 1186/1748-5908-4-61.

10. LaRocca R, Yost J, Dobbins M, Ciliska D, Butt M. The effectiveness of knowledge translation strategies used in public health: a systematic review. BMC Public Health. 2012:12

11. Lavis JN, Ross SE, Hurley JE. Examining the role of health services research in public policymaking. Milbank Q. 2002;80(1):125-54.

12. Lavis JN. Research, public policymaking, and knowledge-translation processes: Canadian efforts to build bridges. J Contin Educ Health Prof. 2006;26(1):37-45

13. Klein R. Evidence and policy: interpreting the Delphic oracle. J R Soc Med. 2003;96(9):429-31.

14. Walt G. How far does research influence policy? Eur J Public Health. 1994;4(4):233-5

15. Bucknall $T$, Fossum $M$. It is not that simple nor compellingl: comment on "translating evidence into healthcare policy and practice: single versus multi-faceted implementation strategies - is there a simple answer to a complex question?". Int J Health Policy Manag. 2015;4(11):787

16. Bowen S, Erickson T, Martens PJ, Crockett S. More than "using research": the real challenges in promoting evidence-informed decision-making. Healthc Policy. 2009:4(3):87.

17. Macintyre S, Petticrew M. Good intentions and received wisdom are not enough. J Epidemiol Community Health. 2000;54(11):802-3.

18. Chalmers I. Trying to do more good than harm in policy and practice: the role of rigorous, transparent, up-to-date evaluations. Ann Am Acad Pol Soc Sci. 2003;589(1):22-40. https://doi.org/10.1177/0002716203254762.

19. Grimshaw JM, Eccles MP, Lavis JN, Hill SJ, Squires JE. Knowledge translation of research findings. Implementation science. 2012;7(1):50.

20. Peters DH, Adam T, Alonge O, Agyepong IA, Tran N. Implementation research: what it is and how to do it. Bmj. 2013;347:f6753. doi:10.1136/bmj. f6753.
21. Stone EG, Morton SC, Hulscher ME, Maglione MA, Roth EA, Grimshaw JM, et al. Interventions that increase use of adult immunization and cancer screening services: a meta-analysis. Ann Intern Med. 2002;136(9):641-51.

22. Paramonczyk A. Barriers to implementing research in clinical practice. Can Nurse. 2005;101(3):12-5.

23. Haynes B, Haines A. Barriers and bridges to evidence based clinical practice. BMJ : Br Med J 1998;317(7153):273-276.

24. Lavis JN. How can we support the use of systematic reviews in policymaking? PLoS Med. 2009;6(11):e1000141.

25. Wilson PM, Watt IS, Hardman GF. Survey of medical directors' views and use of the Cochrane Library. Br J Clin Gov. 2001;6(1):34-9.

26. Ram FS, Wellington SR. General practitioners use of the Cochrane Library in London. Prim Care Respir J. 2002:11(4):123-5.

27. Dobbins M, Cockerill R, Barnsley J. Factors affecting the utilization of systematic reviews: A study of public health decision makers. International journal of technology assessment in health care. 2001;17(2):203-14.

28. Innvær S, Vist G, Trommald M, Oxman A. Health policy-makers' perceptions of their use of evidence: a systematic review. J Health Serv Res Policy. 2002;7(4):239-44.

29. Murthy L, Shepperd S, Clarke MJ, Garner SE, Lavis JN, Perrier L, Roberts NW, Straus SE. Interventions to improve the use of systematic reviews in decision-making by health system managers, policy makers and clinicians. Cochrane Database of Systematic Reviews. 2012:(9):CD009401. doi:10.1002/ 14651858.CD009401.pub2.

30. Tetroe JM, Graham ID, Foy R, Robinson N, Eccles MP, Wensing M, et al. Health research funding agencies' support and promotion of knowledge translation: an international study. Milbank Q. 2008;86(1):125-55. https://doi. org/10.1111/j.1468-0009.2007.00515.x

31. Perrier L, Mrklas K, Lavis JN, Straus SE. Interventions encouraging the use of systematic reviews by health policymakers and managers: a systematic review. Implement Sci. 2011;6:43. https://doi.org/10.1186/ 1748-5908-6-43.

32. Mitton C, Adair CE, McKenzie E, Patten SB, Waye Perry B. Knowledge transfer and exchange: review and synthesis of the literature. Milbank Q. 2007:85(4): 729-68. https://doi.org/10.1111/j.1468-0009.2007.00506.x.

33. Armstrong R. Evidence-informed public health decision-making in local government [PhD thesis]. Melbourne: University of Melbourne; 2011

34. McKibbon KA, Lokker C, Wilczynski NL, Ciliska D, Dobbins M, Davis DA, et al. A cross-sectional study of the number and frequency of terms used to refer to knowledge translation in a body of health literature in 2006: a tower of Babel? Implement Sci. 2010;5:16. https://doi.org/10.1186/1748-5908-5-16.

35. McKibbon KA, Lokker C, Wilczynski NL, Haynes RB, Ciliska D, Dobbins M, et al. Search filters can find some but not all knowledge translation articles in MEDLINE: an analytic survey. J Clin Epidemiol. 2012;65(6):651-9. https://doi. org/10.1016/j.jclinepi.2011.10.014.

36. Lokker C, McKibbon KA, Wilczynski NL, Haynes RB, Ciliska D, Dobbins M, et al. Finding knowledge translation articles in CINAHL. Stud Health Technol Inform. 2010;160(Pt 2):1179-83.

37. Science I. About. 2016. http://implementationscience.biomedcentral.com/ about. Accessed 19 Jun 2016

38. Kirkpatrick DL. Evaluating human relations programs for industrial foremen and supervisors. Madison: University of Wisconsin; 1954.

39. Covidence. 2016. https://www.covidence.org/. Accessed 18 Nov 2016.

40. Higgins JP, Altman DG, Gøtzsche PC, Jüni P, Moher D, Oxman AD, et al. The Cochrane Collaboration's tool for assessing risk of bias in randomised trials. BMJ. 2011;343:d5928.

41. NHLBI. (2014, February). Background: Development and use of study quality assessment tools. US department of Health and Human Services. Retrieved from http://www.nhlbi.nih.gov/health-pro/guidelines/in-develop/ cardiovascular-risk-reduction/tools/background.

42. CASP. NHS Critical Appraisal Skills Programme (CASP): appraisal tools. NHS Public Health Resource Unit. 2017. http://www.casp-uk.net/casp-tools-checklists.

43. Thomas J, Harden A. Methods for the thematic synthesis of qualitative research in systematic reviews. BMC Med Res Methodol. 2008:8:45. https://doi.org/10.1186/1471-2288-8-45.

44. Bradley EH, Curry LA, Devers KJ. Qualitative data analysis for health services research: developing taxonomy, themes, and theory. Health Serv Res. 2007; 42(4):1758-72.

45. Janesick $V$. The choreography of qualitative research: minuets, improvisations, and crystallization. In: Denzin N, Lincoln Y, editors. Strategies of qualitative inquiry. 2nd ed. Ed. Thousand Oaks: Sage Publications; 2003. p. 46-79. 
46. Beynon P, Chapoy C, Gaarder M, Masset E. What difference does a policy brief make? Full report of an IDS, 3ie, Norad study. Institute of Development Studies and the International Initiative for Impact Evaluation (3ie): New Delhi, India. 2012. http://www.3ieimpact.org/media/filer_public/2012/08/22/ fullreport_what_difference_does_a_policy_brief_make_2pdf_-_adobe_ acrobat_pro.pdf.

47. Brownson RC, Ballew P, Brown KL, Elliott MB, Haire-Joshu D, Heath GW, et al. The effect of disseminating evidence-based interventions that promote physical activity to health departments. Am J Public Health. 2007;97(10):1900-7.

48. Bullock A, Morris ZS, Atwell C. Exchanging knowledge through healthcare manager placements in research teams. Serv Ind J. 2013;33(13-14):1363-80.

49. Campbell D, Donald B, Moore G, Frew D. Evidence check: knowledge brokering to commission research reviews for policy. Evid Policy. 2011;7 https://doi.org/10.1332/174426411×553034.

50. Kitson A, Silverston H, Wiechula R, Zeitz K, Marcoionni D, Page T. Clinical nursing leaders', team members' and service managers' experiences of implementing evidence at a local level. J Nurs Manag. 2011;19(4):542-55. https://doi.org/10.1111/j.1365-2834.2011.01258.x.

51. Waqa G, Mavoa H, Snowdon W, Moodie M, Schultz J, McCabe M. Knowledge brokering between researchers and policymakers in Fiji to develop policies to reduce obesity: a process evaluation. Implement Sci. 2013;8 https://doi.org/10.1186/1748-5908-8-74.

52. Dagenais C, Some TD, Boileau-Falardeau M, McSween-Cadieux E, Ridde V. Collaborative development and implementation of a knowledge brokering program to promote research use in Burkina Faso, West Africa. Glob Health Action. 2015;8:26004. doi:10.3402/gha.v8.26004

53. Flanders SA, Kaufman SR, Saint S, Parekh VI. Hospitalists as emerging leaders in patient safety: lessons learned and future directions. J Patient Saf. 2009;5(1):3-8.

54. Uneke CJ, Ndukwe CD, Ezeoha AA, Uro-Chukwu HC, Ezeonu CT. Implementation of a health policy advisory committee as a knowledge translation platform: the Nigeria experience. Int J Health Policy Manag. 2015; 4(3):161-8. 10.15171/ijhpm.2015.21.

55. Döpp CM, Graff MJ, Rikkert MGO, van der Sanden MWN, Vernooij-Dassen MJ. Determinants for the effectiveness of implementing an occupational therapy intervention in routine dementia care. Implement Sci. 2013;8(1):1.

56. Gagliardi AR, Fraser N, Wright FC, Lemieux-Charles L, Davis D. Fostering knowledge exchange between researchers and decision-makers: exploring the effectiveness of a mixed-methods approach. Health Policy. 2008;86(1):53-63.

57. Traynor R, DeCorby K, Dobbins M. Knowledge brokering in public health: a tale of two studies. Public Health. 2014;128(6):533-44.

58. Chambers D, Grant R, Warren E, Pearson S-A, Wilson P. Use of evidence from systematic reviews to inform commissioning decisions: a case study. Evid Policy. 2012;8(2):141-8.

59. Champagne F, Lemieux-Charles L, Duranceau M-F, MacKean G, Reay T. Organizational impact of evidence-informed decision making training initiatives: a case study comparison of two approaches. Implement Sci. 2014;9(1):53

60. Courtney KO, Joe GW, Rowan-Szal GA, Simpson DD. Using organizational assessment as a tool for program change. J Subst Abus Treat. 2007;33(2):131-7.

61. Dobbins M, Cockerill R, Barnsley J, Ciliska D. Factors of the innovation, organization, environment, and individual that predict the influence five systematic reviews had on public health decisions. Int J Technol Assess Health Care. 2001;17(4):467-78.

62. Waqa G, Mavoa H, Snowdon W, Moodie M, Nadakuitavuki R, Mc Cabe M. Participants' perceptions of a knowledge-brokering strategy to facilitate evidence-informed policy-making in Fiji. BMC Public Health. 2013;13 https:// doi.org/10.1186/1471-2458-13-725.

63. Moat KA, Lavis JN, Clancy SJ, El-Jardali F, Pantoja T. Evidence briefs and deliberative dialogues: perceptions and intentions to act on what was learnt. Bull World Health Organ. 2014;92(1):20-8.

64. Wilson MG, Grimshaw JM, Haynes RB, Hanna SE, Raina P, Gruen R, et al. A process evaluation accompanying an attempted randomized controlled trial of an evidence service for health system policymakers. Health Res Policy Syst. 2015:13(1):78

65. Kotter JR. Leading change — why transformation efforts fail. Harv Bus Rev. 2007;85(1):96-103.

66. Whelan-Berry KS, Somerville KA. Linking change drivers and the organizational change process: a review and synthesis. J Chang Manag. 2010;10(2):175-93.
67. Trice HM, Beyer JM. Cultural leadership in organizations. Organ Sci. 1991;2(2):149-69.

68. Downs A, Besson D, Louart P, Durant R, Taylor-Bianco A, Schermerhorn Jr J. Self-regulation, strategic leadership and paradox in organizational change. J Organ Chang Manag. 2006;19(4):457-70

69. Jones N, Walsh C. Policy briefs as a communication tool for development research: Overseas development institute (ODI); 2008.

70. Schneider B, Gunnarson SK, Niles-Jolly K. Creating the climate and culture of success. Organ Dyn. 1994;23(1):17-29.

71. Whelan-Berry K, Alexander P. Creating a culture of excellent service: a scholar and practitioner explore a case of successful change. Paper presented at the Academy of Management. Honolulu, August; 2005.

72. Bennett JB, Lehman WE, Forst JK. Change, transfer climate, and customer orientation a contextual model and analysis of change-driven training. Group Org Manag. 1999:24(2):188-216.

73. Mansouri M, Lockyer J. A meta-analysis of continuing medical education effectiveness. J Contin Educ Heal Prof. 2007;27(1):6-15. https://doi.org/10. 1002/chp.88.

74. Marinopoulos SS, Dorman T, Ratanawongsa N, Wilson LM, Ashar BH, Magaziner $J$, et al. Effectiveness of continuing medical education. Evid Rep Technol Assess. 2007;149:1-69.

75 Chambers D, Wilson PM, Thompson CA, Hanbury A, Farley K, Light K. Maximizing the impact of systematic reviews in health care decision making: a systematic scoping review of knowledge-translation resources. Milbank Q. 2011;89(1):131-56.

76 Armstrong R, Waters E, Dobbins M, Lavis JN, Petticrew M, Christensen R. Knowledge translation strategies for facilitating evidence-informed public health decision making among managers and policy-makers. Cochrane Database of Systematic Reviews. 2011;(6):CD009181. doi:10.1002/14651858. CD009181.

77 Treweek S, Oxman AD, Alderson P, Bossuyt PM, Brandt L, Brożek J, et al. Developing and evaluating communication strategies to support informed decisions and practice based on evidence (DECIDE): protocol and preliminary results. Implement Sci. 2013;8(1):6.

78 Phillips SJ. Piloting knowledge brokers to promote integrated stroke care in Atlantic Canada, Evidence in action, acting on evidence; 2008. p. 57.

79 Lyons R, Warner G, Langille L, Phillips S. Evidence in action, acting on evidence: a casebook of health services and policy research knowledge translation stories: Canadian Institutes of Health Research; 2006.

80 Merlin T, Weston A, Tooher R. Extending an evidence hierarchy to include topics other than treatment: revising the Australian 'levels of evidence'. BMC medical research methodology. 2009;9:34. doi:10.1186/1471-2288-9-34

\section{Submit your next manuscript to BioMed Central and we will help you at every step:}

- We accept pre-submission inquiries

- Our selector tool helps you to find the most relevant journal

- We provide round the clock customer support

- Convenient online submission

- Thorough peer review

- Inclusion in PubMed and all major indexing services

- Maximum visibility for your research

Submit your manuscript at www.biomedcentral.com/submit 